\title{
ESTRESSORES VIVENCIADOS POR MULHERES MASTECTOMIZADAS INTEGRANTES DE UM GRUPO DE APOIO*
}

Eniva Miladi Fernandes Stumm ${ }^{1}$, Cristiane Maçalai², Marinês Tambara Leite ${ }^{3}$, Cleci Lourdes Schmidt Piovesan Rosanelli ${ }^{4}$

RESUMO: Este estudo identificou estressores vivenciados por seis mulheres mastectomizadas, integrantes de um grupo de apoio. Configura-se como pesquisa de abordagem qualitativa. Os dados foram coletados por meio de observação e de entrevista aberta, e analisados seguindo os passos da análise temática, tendo emergido uma categoria: Re-conhecendo os estressores vivenciados por mulheres mastectomizadas. Os resultados possibilitam entender o que leva as mulheres a vivenciar o estresse e podem contribuir para que profissionais da saúde e estudantes reflitam e compreendam essa situação, no sentido de manter um relacionamento de proximidade, criar espaço qualificado de escuta, e assim amenizar os estressores e melhorar o bem-estar físico e emocional de mulheres mastectomizadas.

PALAVRAS-CHAVE: Mastectomia; Estresse psicológico; Mulheres; Assistência de enfermagem.

\section{STRESSORS EXPERIENCED BY MASTECTOMIZED WOMEN MEMBERS OF A SUPPORT GROUP}

\begin{abstract}
This study identified stressors experienced by six women who had mastectomy, members of a support group. It is a qualitative study. Data were collected through observation and open interviews, and analyzed following the steps of the thematic analysis technique, emerging as a category: Re-learning the stressors experienced by women with mastectomy. These results enable us to understand what drives women to experience stress and can contribute to health professionals and students to reflect and understand the situation, to maintain a close relationship, create qualified space for listening, and thus alleviate the stressors and improve the physical well-being and emotional development of women with mastectomy.
\end{abstract}

KEYWORDS: Mastectomy; Stress, psychological; Women; Nursing care.

\section{ESTRESORES VIVIDOS POR MUJERES MASTECTOMIZADAS INTEGRANTES DE UN GRUPO DE APOYO}

RESUMEN: Este estudio identificó estresores vividos por seis mujeres que pasaron por mastectomía, integrantes de un grupo de apoyo. Se configura como investigación de abordaje cualitativo. Los datos fueron recogidos por medio de observación y de entrevista abierta, y analizados según los pasos del análisis temático, emergiendo una categoría: Reconociendo los estresores vivenciados por mujeres mastectomizadas. Los resultados posibilitan entender lo que lleva las mujeres a vivir el estrese y pueden contribuir para que profesionales de la salud y estudiantes reflexionen y comprendan esa situación, en sentido de mantener una relación de proximidad, crear espacio cualificado de escucha y, así, amenizar los estresores y mejorar el bienestar físico y emocional de mujeres mastectomizadas.

PALABRAS CLAVE: Mastectomía; Estrés Psicológico; Mujeres; Asistencia de enfermería.

\footnotetext{
*Texto produzido a partir de resultados de Trabalho de Conclusão do Curso de Graduação em Enfermagem da Universidade Regional do Noroeste do Estado do Rio Grande do Sul-Unijuí.

${ }^{1}$ Enfermeira. Mestre em Administração. Docente da Unijuí.

${ }^{2}$ Enfermeira da Rede Básica de Saúde do Município de Chiapetta-RS.

${ }^{3}$ Enfermeira. Doutora em Gerontologia Biomédica. Docente da Universidade Federal de Santa Maria-UFSM e do Centro de Educação Superior Norte-CESNORS.

${ }^{4}$ Enfermeira. Mestre em Educação nas Ciências. Docente da Unijuí.
}

Autor correspondente:

Eniva Miladi Fernandes Stumm

Universidade Regional do Noroeste do Estado do Rio Grande do Sul

Rua 20 de Setembro, 902 - 98700-000 - Ijui-RS, Brasil

Recebido: $14 / 04 / 10$

E-mail: eniva@unijui.edu.br

Aprovado: 02/06/10

Cogitare Enferm. 2010 Jul/Set; 15(3):492-9 


\section{INTRODUÇÃO}

Estimativas do Instituto Nacional de Câncer (INCA) apontam que o câncer de mama é o responsável pelo maior número de mortes entre as mulheres e o mais temido pelas mesmas, devido à sua alta frequência e ao impacto negativo sobre a percepção da feminilidade, da sexualidade e da autoestima, mais do que qualquer outro tipo de neoplasia ${ }^{(1)}$.

Frente ao diagnóstico de câncer de mama, a mulher e seus familiares passam a vivenciar uma série de etapas, as quais implicam em dor, sofrimento, negação, medo, aceitação, sublimação, entre outros sentimentos. Uma etapa inevitável é a hospitalização que, por si só, pode se constituir em uma situação geradora de ansiedade e de estresse. Esta situação, aliada à necessidade da mulher ser submetida à mastectomia, contribui para exacerbar o estresse, com repercussões no tratamento e na reabilitação.

O período cirúrgico talvez seja o mais estressante pois, embora a tendência atual consista na realização de intervenção cirúrgica conservadora, inúmeros casos requerem mastectomia radical. Nessa condição, a mulher é confrontada definitivamente com a perda da mama, com o medo da intervenção, da mutilação e da morte, sentimentos que favorecem o surgimento e manutenção de níveis elevados de estresse ${ }^{(2)}$.

Nesse contexto, destaca-se a atuação da Enfermagem no cuidado às pacientes, por meio do conhecimento das reais necessidades e intervenções cuidativas. O contato da equipe de enfermagem com o paciente oncológico permite modificar as atitudes e condutas frente às próprias dificuldades e limitações, contribui para que os integrantes da equipe ampliem sua visão e percebam que há pessoas vivenciando grandes sofrimentos e mesmo assim continuam a lutar para que a vida vença ${ }^{(3)}$. Pela proximidade com a doente, a Enfermagem tem oportunidade de prestar cuidado integral e personalizado, permeado por uma relação de confiança, esclarecimento de dúvidas e minimização de estressores ${ }^{(2)}$. Vale lembrar que a definição do que seja estresse, pela equipe de saúde, é fundamental para o planejamento de ações eficazes que possibilitem a sua redução.

Estresse é qualquer situação na qual uma demanda não específica exige que o indivíduo reaja e tome uma atitude. É uma situação tensa, fisiológica ou psicológica, que pode afetar a pessoa em todas as dimensões humanas. Já a resposta é influenciada pela intensidade, duração, âmbito e número de estressores presentes no momento da ocorrência da situação desencadeante de estresse ${ }^{(4)}$.

$\mathrm{Na}$ literatura brasileira são poucos os estudos que abordam a temática relativa ao estresse vivenciado por mulheres que se submeteram à mastectomia. Entende-se que as mulheres com diagnóstico de câncer de mama, submetidas à radioterapia e quimioterapia, vivenciam situações que podem contribuir para o estresse. Daí a necessidade de ações de enfermagem qualificadas, que contribuam para a promoção do bem-estar e minimização do sofrimento. Para tanto, pesquisas que buscam estudar e discutir esses aspectos são relevantes.

Este estudo teve como objetivo identificar estressores vivenciados por mulheres mastectomizadas, integrantes de um grupo de apoio.

\section{METODOLOGIA}

Trata-se de um estudo de abordagem qualitativa, realizado com mulheres participantes do grupo de apoio "Amigas do Peito", grupo vinculado a um hospital localizado em um município da região noroeste do Estado do Rio Grande do Sul, Brasil. Vale destacar que este é o único grupo de apoio a mulheres mastectomizadas do município, que conta com uma população de aproximadamente 80 mil habitantes. No período do estudo, 23 mulheres participavam do grupo de apoio. Os encontros grupais ocorrem mensalmente, com duração de duas horas, coordenados por uma enfermeira, uma fisioterapeuta e uma psicóloga.

A amostra, do tipo aleatório, constituiu-se de seis mulheres que preencheram os critérios de inclusão: ter se submetido à mastectomia; ser integrante do grupo de apoio e aceitar fazer parte da pesquisa. Para a coleta das informações utilizou-se entrevista semiestruturada, gravada em meio digital e posteriormente transcrita na íntegra. A entrevista ocorreu em horários previamente agendados e em locais de preferência das mulheres: cinco foram realizadas no domicílio da entrevistada e uma no hospital, no período de agosto a outubro de 2006. Além disso, foi utilizado o diário de campo, no qual foram registradas reações, atitudes e gestos que não puderam ser captados por meio do diálogo. O número de entrevistas foi definido pelo método de exaustão, ou seja, quando nenhum dado novo foi acrescido ao que já havia sido obtido.

A análise das informações seguiu os preceitos da análise temática ou categorial, conforme orientação

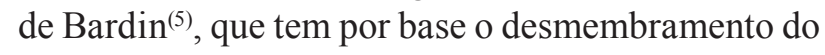


texto em unidades, isto é, identificação dos diferentes núcleos de sentido que constituem a comunicação e, na sequência, seu reagrupamento em categorias, análise e interpretação das informações.

Foram observados os aspectos éticos, sendo o projeto de pesquisa aprovado pelo Comitê de Ética em Pesquisa da Universidade Regional do Noroeste do Estado do Rio Grande do Sul, sob o Parecer Consubstanciado n. 102/2006. No intuito de manter o anonimato das participantes, as identificamos com codinomes indígenas, pelo significado de vida e natureza que cada um representa: Araci (Mãe do Dia), Bêni (Rio), Ceci (Mãe Superior), Jaci (Lua), Janaina (Rainha dos Lares) e Rudá (Deusa do Amor).

\section{RESULTADOS E DISCUSSÃO}

A idade das mulheres variou de 40 a 80 anos, quatro eram casadas, uma solteira e uma viúva. Uma delas possuia oito filhos, quatro tinham dois filhos e uma não possuia descendentes. Em relação à escolaridade, a maioria cursou o ensino médio. $\mathrm{O}$ tempo de realização da mastectomia variou de seis meses a 20 anos, todas realizaram quimioterapia e radioterapia e somente uma realizou implante de prótese mamária. Quanto à participação no grupo, o tempo variou de dois meses a três anos, sendo que a maioria frequentava há dois anos.

Ao analisar o conteúdo dos depoimentos das entrevistadas, aglutinado por convergência de ideias em uma categoria de análise, foi possível identificar os estressores vivenciados pelas mulheres, apresentados e discutidos abaixo.

\section{Re-conhecendo os estressores vivenciados por mulheres mastectomizadas}

A doença é um acontecimento inesperado na vida das pessoas, desencadeadora de inúmeros sentimentos, tanto nos pacientes quanto nos familiares e que proporcionou sensações desagradáveis, por envolver uma situação nova, que exige adaptação. Cada indivíduo reage de modo ímpar a essa condição, uma vez que isso depende de fatores como expectativas, história de vida e vivências cotidianas.

Essas situações vivenciadas pela mulher podem ser responsáveis por sofrimento psíquico, evoluindo para o físico, espiritual e social. Assim, considera-se importante compreender o adoecimento como um processo que abarca componentes biológicos, psicológicos, ambientais sociais e espirituais. No que tange ao câncer, especificamente, o momento da confirmação da doença pode desencadear sentimentos e reações diferenciadas. Dificilmente existe uma patologia que induza tantos sentimentos negativos, em qualquer um dos seus estágios, quanto o câncer ${ }^{(6)}$. Nos depoimentos de Araci e Bêni, evidencia-se que as reações frente ao diagnóstico de câncer de mama foram de desespero, nervosismo, apreensão, estresse, dentre outros.

Quando eu soube, não foi muito bom! Fiquei nervosa, estressada, ai fiz a biópsia. Então não foi fácil. Quando o doutor me contou, me atirei na cama e comecei a chorar. E eu estava sozinha, quase fui atropelada na rua. Não é fácil a gente pensar uma coisa, e é outra. (Araci)

Daí, quando veio o resultado, ela [a médica] disse que era maligno. Eu entrei num desespero, comecei a chorar sem parar. (Bêni)

Neste estudo se evidencia que a reação das mulheres diante da confirmação do diagnóstico de câncer e, consequentemente, da intervenção terapêutica, a mastectomia, divergem. Uma das entrevistadas inicialmente sofreu com a confirmação da doença, porém, gradativamente, aceitou o fato e se preparou para a cirurgia, tanto que ao ser submetida à mastectomia, estava confiante, calma e sem medo. Outro aspecto importante em seu depoimento foi o fato de ela admitir que o estresse emergiu após a realização da cirurgia.

Bem, quando eu soube foi um choque, mas como era uma necessidade fazer a cirurgia, eu fui compreendendo a situação, e quando chegou a fase da cirurgia, eu fiz. Tava calma, não tive nada, não tive medo, estava tranquila. Foi tudo muito bem. Depois da cirurgia é que eu fiquei bastante estressada. (Ceci)

No depoimento de Ceci identifica-se a nãomanifestação verbal de que teve a ajuda dos profissionais da saúde, mas sim da forma como ela reagiu frente à cirurgia. Provavelmente, ela teve acompanhamento, esclarecimento e apoio dos profissionais no perioperatório. É de suma importância a identificação dos sentimentos das pacientes, particularmente no pré-operatório de mastectomia; estar atento para a identificação precoce das complicações. $O$ enfermeiro, no papel de orientador, identifica e supre as necessidades de aprendizagem do paciente, e este poderá alterar o seu comportamento de saúde, o que favorecerá uma melhor qualidade da assistência ${ }^{(7)}$. 
A mulher com câncer de mama necessita de auxílio dos profissionais de saúde, uma vez que muitas delas ficam amedrontadas em relação à doença, talvez pela ideia de que, socialmente, ainda se pensa que esta morbidade impõe dor, sofrimento, mutilação e morte. Esses medos são aspectos que podem limitar a aceitação do tratamento e a promoção da saúde ${ }^{(8)}$.

Outro estressor vivenciado pelas mulheres refere-se à hospitalização, especificamente a relacionada à cirurgia. Nesse momento, inúmeros sentimentos e sensações as acometem, pois o hospital é um ambiente desconhecido, que implica em afastamento da família, mudanças nas atividades diárias e restrições impostas pela instituição e também pela doença. As pessoas no hospital ficam expostas a um ambiente estranho e impessoal, no qual o relacionamento dos profissionais de saúde caracteriza-se pela distância, formalidade, informações rápidas e utilização de terminologias técnico-científicas ${ }^{(9)}$.

O medo da morte no pré-operatório de mastectomia foi outro estressor vivenciado pelas pacientes. A morte pode provocar temor, angústia e resultar em um desejo de fugir do assunto, contudo, ela integra a vida. O profissional da saúde necessita de recursos que o auxiliem a lidar com essa situação e que ele continue a cuidar dos pacientes ${ }^{(10)}$.

Bêni, em seu depoimento, faz menção ao medo da morte, sentido quando se internou para ser submetida à mastectomia e, especificamente, ao receio de morrer durante a cirurgia, sentimento que também atinge os familiares:

Ai eu fiquei [...] mas quando eu cheguei no hospital para fazer, dai eu entrei em desespero, porque eu achei que ia morrer na sala de cirurgia. Aí, ela [a médica] conversou comigo antes de ir para a sala de cirurgia e disse 'vamos, vai com calma'. Daifizeram. As minhas filhas vieram e disseram que eu ia morrer, que eu não ia viver, disseram que eu estava como morta deitada na cama. (Bêni)

Ainda no depoimento de Bêni observa-se que os familiares, em especial as filhas, não possuíam condições psicológicas de lhe prestar apoio, pois também se encontravam com medo. Muitas vezes, a família fica tão abalada com a doença e o tratamento, que sofre um desequilíbrio e não tem possibilidade de oferecer o apoio de que a mulher necessita ${ }^{(11)}$.

Sequencialmente, no depoimento de Jaci, emerge o sofrimento vivenciado, aliado ao fato de ter que ser submetida à mutilação pela mastectomia total, situação causadora de ansiedade e de estresse, como ela própria identifica:

$O$ que me causou maior sofrimento, ansiedade $e$ estresse foi o impacto de saber que tinha que fazer a cirurgia, e por ser total. Ficar mutilada. (Jaci)

É importante que o conhecimento do significado da mutilação, para as mulheres que a vivenciam, esteja claro aos profissionais da saúde, para que possam reconhecer a representação dele no contexto de vida das mesmas, por ocasião da alta hospitalar e ao retornarem aos seus domicílios, na sua recuperação ${ }^{(12)}$.

Já em relação a outro estressor - a ansiedade - a cirurgia e a anestesia são situações impostas e que exigem enfrentamento. É possível que a antecipação imaginária destes eventos desencadeie sentimentos que, influenciados pelas diferenças individuais, resultem em comportamentos peculiares de ajustes, cuja finalidade é enfrentar o estresse e a ansiedade ${ }^{(13)}$.

Após a cirurgia de mastectomia, a paciente enfrenta outros estressores, pois tem conhecimento de que após a hospitalização vem a fase de recuperação, assim, começa um novo processo de adaptação à situação. O pós-operatório é marcado pelo medo da dor, dos curativos, do retorno da doença, de enfrentar a mutilação, tudo isso aliado à preocupação com a feminilidade afetada e as reações do companheiro(2).

No depoimento de Bêni, emergiram vários estressores, entre eles a dor física, o medo e a insegurança. Ela teve uma complicação pós-cirúrgica, necessitou de enxertia e esse fato a estressou, contribuindo para exacerbar seu sofrimento:

E daí, quando a doutora me operou, ela amarrou o meu braço. E daí, morreu aquela parte ali, bem onde era o seio, ficou um buraco. Ai tive que ir, cada dia, para reviver aquela parte. Quando eu ia fazer aquilo, me dava um medo de entrar lá, porque aquilo era dolorido, era na dura sorte. Ele não fazia nada de anestesia, coisa nenhuma, ele picava até fazer sangrar; enquanto não sangrava bem, ele não parava. Daí, era todo o dia, um mês, eu ia todos os dias. Depois, ele tirou da coxa e fez o enxerto ali, onde reviveu aquela parte de novo. (Bêni)

No diálogo com Bêni, o tempo já transcorrido da realização da cirurgia, que era de vinte anos, parece não ter colaborado para minimizar o sofrimento, pois 
sua fala foi carregada de emoção. Vale destacar que, após a mastectomia, dependendo da evolução e da indicação médica, a mulher possui a opção de reconstrução mamária. Esta é uma alternativa para restabelecer a imagem corporal e melhorar a autoimagem, já que a mastectomia mutila um órgão que simboliza a feminilidade, a sexualidade e a maternidade ${ }^{(14)}$.

Considera-se importante destacar o depoimento de Jaci, diferente dos de Bêni e de Rudá, no qual ela menciona que ser submetida à mastectomia significou uma experiência dolorosa e única, pois apresentou complicações três anos após, quando teve metástase óssea. Em seu depoimento, percebe-se intenso sofrimento emocional, que permanece e se sobressai ao físico:

O caroço era muito grande. Era no bico do seio, e depois o processo da quimio, da radio, da recuperação, tudo foi bem comovente pra gente. Era inexperiente, jamais pensei que iria acontecer comigo. Isso causou bastante dor (choro). A gente fica emocionada, de saber que aconteceu logo comigo. (Jaci)

O conjunto de estressores que a paciente enfrenta no pré e pós-cirúrgico são determinantes para sua recuperação, pois a mastectomia se reflete no físico e no psíquico da mulher. Ela passa por conflito psicoemocional quando realiza uma reflexão acerca da vida, conceitos, valores e atitudes relacionados à si e à sociedade. Sua identidade está difusa, uma vez que deixa de ser a mulher, mãe, esposa, profissional e passa a ser identificada como doente, com câncer, mastectomizada, mutilada. Contudo, esta ideia pode ser quebrada ao se trabalhar e motivar a mulher na busca e resgate de sua personalidade e autoestima, retomando características próprias como capacidade, feminilidade, sexualidade, sonhos, potenciais e realizações ${ }^{(15)}$.

Evidencia-se que todas as etapas, desde o diagnóstico, tratamento e reabilitação, resultam em algum grau de sofrimento para as mulheres. A recuperação é dolorosa, devido a complicações comuns que ocorrem no pós-operatório e às alterações desencadeadas na imagem corporal. Destaca-se a importância dos profissionais da saúde estimularem a paciente a participar do tratamento, a estar presente nas decisões e a fazer perguntas.

As modalidades de tratamento à mulher com câncer de mama incluem quimioterapia, radioterapia, imunoterapia, dentre outros. Nesse estudo, percebe-se que os efeitos colaterais decorrentes da quimioterapia foram desencadeadores de estresse. Os mais citados foram: anemia, náusea, êmese, diarreia, fadiga, fraqueza, alopécia e mal-estar.

Depois da cirurgia, eu fiz seis sessões de quimio. Fiz três, e na terceira eu já fiquei um pouco anêmica. Ai parei e, nesse tempo que parei, eu fiz as radioterapias. Foram cinquenta e sete aplicações e aí, dali tudo bem. A quimio para mim foi horrivel [...] porque passava até dez dias com aqueles vômitos, náuseas. (Ceci)

A mulher mastectomizada, quando em tratamento para o câncer, tende a ficar mais sensível e vulnerável a qualquer estímulo e, muitas vezes, ela interfere na promoção de uma resposta eficaz diante desses mesmos estímulos, o que contribui, de forma negativa, para a sua adaptação ${ }^{(16)}$. No depoimento de Rudá, o que lhe causou mais sofrimento foi a perda da mama e a alopécia, como efeito colateral da quimioterapia. Ela também expressa que foi difícil reagir e superar esses eventos, mesmo com o apoio da família:

A perda da mama foi o meu maior sofrimento. E o outro foi a queda de cabelo. Foi bem difícil para superar, mesmo com apoio de minha família. A maior perda foi a do cabelo, mas também limitaram bastante as saídas, inclusive nas duas últimas. Eu tive anemia profunda, que dificultou até caminhar. (Rudá)

A retirada da mama desencadeou várias alterações no cotidiano das mulheres. As mudanças na imagem corporal repercutiram nas atividades diárias e sociais das entrevistadas, contribuindo para o surgimento e manutenção de sentimentos diversos, tais como: vergonha, constrangimento e isolamento.

Mas a pior coisa é a gente perder o cabelo. Fica envergonhada, não queria ir mais à igreja, em lugar nenhum. A gente fica assim, e as pessoas ficam olhando ainda pra gente. (Araci)

E para sair na rua foi bem dificil. Era triste perceber que a família e os amigos se afastaram de mim, porque eu tinha amigos que costumavam ir lá em casa. Mas, no momento que eu estava daquele jeito, não apareceram mais. Isso me deixou muito triste e estressada. (Rudá)

Rudá, além dos sentimentos mencionados, se reporta ao afastamento de familiares e amigos, como estressores importantes e que contribuíram para 
aumentar o sofrimento vivenciado. O câncer é uma doença que afeta não somente as pessoas acometidas, mas também as de suas relações sociais. Cabe destacar que nos dias atuais persiste a associação do termo câncer à morte. $\mathrm{O}$ impacto da mastectomia afeta não apenas a mulher, mas se estende a familiares, colegas de trabalho e amigos, situação que se agrava com a indicação do tratamento: cirurgia, radioterapia e/ou quimioterapia. Além disso, a doença e a mastectomia podem modificar os relacionamentos interpessoais na família $^{(17)}$.

Frequentemente, a mulher pode apresentar ansiedade, agressividade e insegurança. Esses sentimentos emergem permeados de significados, como desesperança, receio, impacto, intercorrências, necessidade de aceitação, de readaptação e de autocuidado $^{(2)}$. Bêni relata seu sofrimento, com sinais de depressão, como consequência do tratamento a que se submeteu. Também agrega a compaixão em relação às demais mulheres que vivenciam o câncer:

Eu não queria que ninguém chegasse perto de mim. Os filhos vinham: "Mãe, o que a mãe tem?". Eu não queria nem conversar com ninguém. Eu estava num nervoso, que Deus o livre. É um desânimo só, porque é triste, muito triste. (Bêni)

Mesmo com os avanços tecnológicos e a eficiência do tratamento para o câncer, em situações estressantes, tais como dor, alterações emocionais e da autoimagem, duração prolongada do tratamento e efeitos colaterais, se constituem em fatores que exigem acompanhamento contínuo dos profissionais da saúde.

Uma situação que contribuiu para o aparecimento de estresse, em uma parcela das pacientes do estudo, foi a necessidade de ter que se afastar do espaço domiciliar, ao deslocar-se para centros de referência em oncologia e, também, permanecer, durante o tratamento, longe do convívio de seus familiares.

Eu achei um desespero ficar sozinha, longe de casa. Eu, na maioria do tempo, chorava. Tinha os filhos pequenos, a guria era pequena. Então, sentia uma tristeza, uma falta dela, o nenê de casa e então o netinho pequeno, ainda, todos os filhos a gente achava falta, do marido longe. Tinha que esperar e ficar longe tanto tempo. sessenta dias. Parecia que era um ano. (Bêni)

Outro fator estressor para as mulheres pesquisadas está relacionado à mudança na aparência física, especialmente a alopécia, como efeito colateral do tratamento quimioterápico, além do sentimento de perda relacionado à amputação da mama. A mama representa a identidade feminina da mulher e a sua remoção denota uma mutilação dolorosa, dos pontos de vista físico e psicológico.

O que mais me marcou, que me deixava desesperada, foi ficar sem cabelo. Para mim, aquilo nem sei explicar [...] não tinha cabelo na cabeça. Eu me senti muito triste, estressada. Às vezes, quando ia ao espelho, eu chorava desesperada de não ter o cabelo, nem o seio. Até hoje eu sinto aquilo. Não posso ficar me olhando no espelho, porque eu tenho que chorar. (Ceci)

Perdi todo o cabelo. Isso sim me deixou muito triste. Me olhava no espelho e me desesperava. Não é fácil também a gente ficar sem o seio. (Janaina)

Nos depoimentos já mencionados se identifica sentimentos de não-aceitação e tristeza pela perda da mama e do cabelo. Ceci foi submetida à mastectomia aos cinquenta e sete anos e, até hoje, aos setenta e sete anos, sofre ao se olhar no espelho e deparar-se sem o seio. Ela destaca a importância do apoio de sua família.

Lidar com o impacto da mastectomia e todo o processo da doença pode interferir nas relações familiares. Rudá não teve apoio familiar; e inclusive, sentiu certa rejeição do cônjuge. Em sua fala, ela deixa transparecer que ele a rejeitava como mulher, por sua imagem corporal estar alterada pela mastectomia:

Eu não tive muito apoio do meu esposo, e às vezes percebia certa rejeição por parte dele. Isso me deixava muito triste [...]. (Rudá)

Neste cenário, cabe ao enfermeiro, pela proximidade na relação com as pacientes, identificar os eventos estressores, na tentativa de auxiliar as mulheres "a lidar" melhor com eles. A equipe de saúde deve estabelecer uma relação de confiança, de aproximação, de compreensão, respeito e apoio para com a paciente que vivencia a doença, o tratamento e a reabilitação, pois ela encontra-se mais fragilizada, angustiada e temerosa.

\section{CONSIDERAÇÕES FINAIS}

O estudo retrata um conjunto de estressores 
vivenciados pelas mulheres, sujeitos da pesquisa, ocasionados pelas diversas situações, as quais vão desde o diagnóstico do câncer de mama, e às expectativas relacionadas ao tratamento cirúrgico, quimioterápico e radioterápico, até o período de reabilitação.

Identificam-se como estressores: confirmação do diagnóstico de câncer; medo da morte; queda de cabelos, como efeito colateral da quimioterapia; autoimagem prejudicada; perda da mama; impacto da notícia aliado à amputação da mama; afastamento da família e dos amigos; dificuldade de aceitação da doença, associada à necessidade de realização de quimioterapia e de radioterapia; presença de metástase, e por isso vivenciar novamente quimioterapia e radioterapia; conviver com as limitações físicas impostas pela doença; afastamento da família em função do tratamento radioterápico; e necessidade de mudar hábitos de vida.

A mastectomia é um processo que implica em mudanças, tanto físicas quanto psicológicas e sociais na vida da mulher e de seus familiares. Essa condição de estar com câncer de mama e ter realizado mastectomia implica em necessidade de adaptação à nova condição o que, em nossa opinião, contribui para o surgimento e manutenção de níveis de estresse, com repercussões no tratamento e na qualidade de vida dessas mulheres.

A construção desse trabalho implicar olhar e compreender a experiência da mulher, de maneira a assimilar os elementos que a definem e a caracterizam. É possível identificar que o sofrimento permeia toda a trajetória da experiência, relacionado com a percepção que a mulher tem de si como portadora de câncer e com a reformulação e construção de uma nova imagem. Este quadro se reflete em um contexto familiar e social.

Quanto à atuação dos profissionais da saúde, destaca-se a importância do relacionamento de proximidade com as pacientes, e a criação de espaço qualificado de escuta, com vistas a amenizar os estressores e melhorar seu bem-estar físico e emocional.

\section{REFERÊNCIAS}

1. Vianna AMSA. Avaliação psicológica de pacientes em reconstrução de mama: um estudo piloto. Estud Psicol. 2004;21(3):203-10.

2. Camargo TC, Souza IEO. Atenção à mulher mastectomizada: discutindo os aspectos ônticos e a dimensão ontológica da atuação da enfermeira no Hospital do Câncer III. Rev Latino-Am Enfermagem. 2003;11(5):614-21
3. Stumm EMF, Leite MT, Maschio G. Vivências de uma equipe de enfermagem no cuidado a pacientes com câncer. Cogitare Enferm. 2008;13(1):75-82.

4. Lipp M. O stress está dentro de você. 5a ed. São Paulo: Contexto; 2003.

5. Bardin L. Análise de conteúdo. Trad. Luís Antero Reto e Augusto Pinheiro. Lisboa: Edições 70; 2002.

6. Deitos TFH, Gaspar JFP. Efeitos biopsicossociais e psiconeuroimunológicos do câncer sobre pacientes e familiares. Rev Bras Cancerol. 1997; 43(2):117-25.

7. Belluomini AS, Tanaka LH. Assistência de enfermagem no pré-operatório de cirurgia cardíaca: percepção dos enfermeiros e auxiliares de enfermagem. Nursing. 2003;10(6):22-9.

8. Regis MF, Simões MFS. Diagnóstico de câncer de mama, sentimentos, comportamentos e expectativas de mulheres. Revista Eletron Enferm. [Internet] 2005;7(01) [acesso em 15 jul 2009]. Disponível: http:// tiny.cc/8ehje

9. Beuter M. Atividade lúcida: uma contribuição para a assistência de enfermagem às mulheres portadoras de câncer. 1996. [dissertação]. Florianópolis (SC): Universidade Federal de Santa Catarina; 1996.

10. Vendruscolo J. Visão da criança sobre a morte. Rev Med. 2005;38(1):26-33.

11. Silva RM, Melo EM, Rodrigues MSP. Família como suporte para mulher em tratamento quimioterápico. Fam Saúde e Desenvolv. [Internet] 1999;1(1/2) [acesso em 15 jul 2009]. Disponível: http://tiny.cc/16pq2

12. Ferreira MLSM, Mamede MV. Representação do corpo na relação consigo mesma após mastectomia. Rev Latino-Am Enfermagem. 2003;11(3):299-304.

13. Peniche ACG, Chaves EC. Algumas considerações sobre o paciente cirúrgico e a ansiedade. Rev LatinoAm Enfermagem. 2000;8(1):45-50.

14. Camargo M, Marx A. Reabilitação no câncer de mama. São Paulo: Roca; 2000.

15. Arantes SL, Mamede MV. A participação das mulheres com câncer de mama na escolha do tratamento: um direito a ser conquistado. Rev Latino-Am Enfermagem. 2003;11(1): 49-58.

16. Yamaguchi C. Câncer de mama: entre de peito nessa 
luta. Reconstrução da mama. 2006. Disponível: http:// www.cancerdemama.org.br

17. Melo EM, Silva RM, Fernandes AFC. O relacionamento familiar após a mastectomia: um enfoque no modo interdependência de Roy. Rev Bras Cancerol. 2005; 51(3):219-25. 